\title{
Idealizing Reduction: \\ The Microfoundations of Macroeconomics
}

\author{
Kevin D. Hoover \\ Departments of Economics and Philosophy \\ Duke University \\ Box 90097 \\ Durham, NC 27708-0097 \\ Tel. (919) 660-1876 \\ E-mailkd.hoover@duke.edu
}

27 May 2008

(7,998 words) 


\section{Abstract}

of

\section{Idealizing Reduction: The Microfoundations of Macroeconomics}

The dominant view among macroeconomists is that macroeconomics reduces to microeconomics - both in the sense that all macroeconomic phenomena arise out of microeconomic phenomena and in the sense that macroeconomic theory - to the extent that it is correct - can be derived from microeconomic theory. More than that the dominant view believes that macroeconomics should in practice used the reduced microeconomic theory: this is the program of microfoundations for macroeconomics to which the vast majority of macroeconomists adhere. The "microfoundational" models that they actually employ are, however, characterized by another feature: they are highly idealized, even when they are applied as direct characterizations of actual data, which itself consists of macroeconomic aggregates. This paper explores the interrelationship between reductionism and idealization in the microfoundational program and the role of idealization in empirical modeling.

JEL codes: B41, E10

Keywords: idealization, reductionism, microfoundations of macroeconomics, macroeconomics, microeconomics, modeling 


\section{Idealizing Reduction: The Microfoundations of Macroeconomics}

\section{Microfoundations}

Economics, since the publication of John Maynard Keynes's General Theory of Employment, Interest, and Money in 1936, has been self-consciously divided into two main branches: microeconomics and macroeconomics. The question of the relationship between the two branches was raised immediately - by Keynes himself, by his critics and by his acolytes (e.g., Keynes 1936, chs. 11 and 13; Leontieff 1936; Klein 1947). Nonetheless, until the early 1970s, a degree of autonomy was widely accepted for each of the two branches. With the rise of the new classical macroeconomics in the mid-1970s, a more radical position began to dominate economics: macroeconomic analysis could be regarded as well-grounded, secure, or reliable only to the extent that it could be appropriately connected to microeconomic analysis (Hoover 1988). Macroeconomics is widely regarded today as standing in need of microfoundations and, indeed, as not being a coequal branch of economics, rather as a derivative and, perhaps, even dispensable mode of economic analysis. The necessity - indeed, even the possibility of microfoundations - has been challenged in a number of different ways. ${ }^{1}$ In this paper, I want to examine the defense offered to one such challenge - namely, the construction of the representative-agent model, the most popular approach to microfoundations, as an idealization of a complete general-equilibrium model of the economy.

Microeconomics is the economics of the behavior of individual economic agents. Typically, microeconomic models or explanations derive the behavior of an economic agent (typically a person, household, or firm) through the optimization of an objective

\footnotetext{
${ }^{1}$ See, for example, Kirman (1992), Janssen (1993), Hartley (1997), Hoover (1995, 2001a, ch. 3, 2001 b, ch. 5 , forthcoming).
} 
function subject to constraints. An agent is modeled as a set of ordered preferences over combinations of consumption goods (where "goods" is interpreted broadly and might, for example, include items not typically traded such as leisure, risk, or prestige). Available combinations of goods are restricted by a budget. Behavior is modeled as the choice of the most preferred attainable combination of goods. Similarly, a firm is typically modeled as maximizing profits subject to the constraints of the available technology.

Microeconomic analysis that treats individuals as optimizing within a wider context that is fixed so that there is no feedback from the choice of the individual to the economy as a whole is called partial equilibrium Partial equilibrium is frequently justified on the assumption that the individual is small relative to the whole, so that feedbacks are negligible. Microeconomics that considers the complete set of interactions that makes up an economy is called general equilibrium. It is still a type of microeconomics, even though there is a sense in which it treats the economy as a whole, since the individual agent remains the driver and there is no place for aggregates.

Macroeconomics addresses the economy as a whole, focusing on the behavior of economic of aggregates, such as gross domestic product (GDP), employment, unemployment, inflation, and interest rates.

At least three distinct theses - with different methodological implications - march under the microfoundational banner:

Thesis 1. Individuals lie behind aggregates in the sense that without individuals there would be no aggregates. Such a weak ontological claim is uncontroversial.

Thesis 2. How individuals behave affects or conditions how aggregates behave. So, it is worth examining individual behavior for insight into aggregate behavior. Such insight 
is typically treated as suggestive and qualitative, rather than restrictive and quantifiable. Keynes himself appeared to subscribe to Thesis 2.

Thesis 3. Aggregates are nothing else but the addition of individual behavior. When the microeconomic properties are taken into proper account, there simply are no residual ontologically distinct or explanatorily efficacious macroeconomic properties.

Thesis 3 is the dominant view in economics today. Sometimes it is regarded aspirationally: good macroeconomics should strive for microfoundations in this sense, though it might not be possible to achieve at present, so that pragmatically we might temporarily have to do with something less satisfactory (see Blanchard and Fischer 1989, ch. 2 and, surprisingly, Lucas 2004). Frequently, Thesis 3 is held aggressively. Some reductions aim to explain the success of one theory or one level of explanation by means of a more fundamental theory but not to eliminate the reduced theory from the practitioner's toolkit. For example, those who believe that the ideal gas laws reduce to statistical mechanics do not claim that the ideal gas laws should be abandoned for practical purposes. In contrast, the advocates of Thesis 3 hold that the only acceptable or useful macroeconomics is microfoundational. ${ }^{2}$ Thesis 3 seeks the ultimate euthanasia of macroeconomics: there is no higher level macroeconomic theory worth preserving for a lower level microecononomic theory to explain.

The appeal of Thesis 3 is partly the result of the conception that most economists hold of what the discipline of economics is. The most popular definition of economics, due to Lionel Robbins (1935, p. 16), sees economics as "the science which studies human

\footnotetext{
${ }^{2}$ Waters (2000), p. 561, describes the physiochemical "imperialists" in genetics as taking as similar position.
} 
behavior as a relationship between scarce means which have alternative uses." Such a definition comes close to saying, "if it is not microeconomics, it is not economics."

More salient perhaps is Robert Lucas's (1976) famous "critique” of econometric policy evaluation. Lucas argued that macroeconometric models - that is, statistically estimated models of the relationships of macroeconomic aggregates - were not identified in the sense that they captured correlations among the data but not the causal structure that generates them. Failure of identification renders such models useless for conditional prediction and, therefore, for policy analysis. Lucas argued that policymakers adopt rules. To the degree that individuals understand these rules, they incorporate them into their own choices. If the rules change, the choices change, and the implied relationships among variables that aggregate those choices also change.

One lesson of the Lucas critique is that conditional inference requires an appropriately causally articulated model. Another lesson is that an appropriate model must capture the intentional actions of economic agents. The fundamental explanatory trope of microeconomics is that ought implies is. Economics on this view is intentional; it must capture the beliefs, expectations, and choices of individual agents. Macroecononomics without microfoundations will fail to do so.

The majority of macroeconomists accept some sort of microfoundational thesis. Radical advocates of Thesis 3 require an implementable reduction of macroeconomics to microeconomics adequate to the Lucas critique. Is any such reduction available? What might it look like? 


\section{Implementing Reduction}

The most popular way of implementing the reduction of macroeconomics to microeconomics is the representative-agent strategy: a single agent or limited number of agents (typical of types or categories of agents), who follow microeconomic rules, stands for the whole economy.

The most straightforward difficulty with representative-agent models is that they typically adopt functional forms for the preferences of the representative agent that directly mimic the forms that microeconomists have found most useful in describing the behavior of individuals. Yet, it is well known that perfect aggregation - the situation in which aggregates behave as scaled up versions of microeconomic quantities - is possible only under conditions that are certainly never realized (Gorman 1953, Hoover 2001a, ch. 3). Perfect aggregation requires homothetic and identical preferences. Identical: you and Bill Gates have the same preferences. Homothetic: Bill Gates, the billionaire, must spend the same proportion of his income on, say, chocolate as would an impoverished Bill Gates. Without perfect aggregation, there is no fixed relationship between the functional forms that might govern aggregates and those that describe the behavior of individuals. These are technical points and are not controversial among economic theorists (see Kirman 1992 and the references therein).

Given the impossibility of perfect aggregation, what then is the appeal of the representative-agent model? Modern macroeconomists frequently appeal to Frank Ramsey's (1928) formulation of the optimal savings problem in which an economy-wide utility function is maximized subject to a production constraint. Whether Ramsey believed that the utility function belonged to a social planner (a Hobbesian Leviathan) or 
was somehow the aggregation of individual utility functions is unclear (see Duarte 2007). Ramsey's analysis is known today as a social-planner problem. As such it neither raises the issue, nor implements a reduction, of microeconomics to macroeconomics. But an argument that is meant to justify it as a microfoundational construction draws on a general equilibrium analysis.

The so-called "second theorem of welfare economics" states that every Pareto optimal distribution can be supported as a competitive equilibrium for some distribution of initial endowments. ${ }^{3}$ The social-planner problem is then seen as a computationally convenient way of summarizing what is in effect a decentralized general equilibrium model - that is, a microeconomic model.

There are a number of problems with this strategy as a serious reduction of macroeconomics to microeconomics. First, if we take the aggregate utility function seriously as belonging to the social planner, decentralization of the planner's program would then require actual redistribution of endowments. In other words, the model is one of a command economy - even if one administered through market transactions - and there is little reason to think that it captures the sort of market economies that are the objects of modeling.

Second, an alternative interpretation assumes that the representative-agent's utility function really does approximate the average preferences of individuals. This amounts to aggregation of preferences, and, once again, perfect aggregation is not possible. Kenneth Arrow's (1951) famous impossibility theory demonstrated that preferences cannot be aggregated in a manner consistent with weak, and intuitively

\footnotetext{
${ }^{3}$ A distribution is Pareto optimal (or efficient) if no reallocation can improve the position of any individual without making some individual worse off.
} 
appealing, regularity conditions. The representative agent's utility function could not represent disparate individual preferences, as Thesis 3 requires.

In fact, third, the decentralization of the social planner problem is typically itself carried out only in a representative manner (see, for example, Blanchard and Fischer 1989, ch. 2). The Leviathan's optimization is shown to be equivalent to an optimization problem with aggregate prices, wages, and interest rates, as if there were markets for GDP, aggregate labor, and aggregate money rather than markets for golf balls, accountants, and particular withdrawals from ATM machines. Finally, to further complicate the problem, the theorem on which the whole strategy rests requires that the conditions of perfect competition be fulfilled. Any market imperfection renders the second theorem of welfare economics false.

Stripped of the support of the decentralization theorem, the representative-agent strategy amounts to the assertion that reduction has been achieved when we posit an agent whose utility derives from various macroeconomic aggregates and who takes national income as his budget. Yet, there are no individual agents and no individual commodities in the model. Rhetoric aside, the model mimics the mathematics of microeconomics without employing its substance.

It is easy to lampoon the representative-agent strategy: it is analogous to providing a reduction of the gas laws to mechanics by modeling a single molecule scaled up to room size (Hoover 2001a, ch. 3). Nevertheless, it is related to a more defensible strategy, which I discuss in detail in Section IV: idealized reduction.

Idealized reduction is more defensible in that it connects the macro to the micro through clear idealizing steps and provides scope for improving the idealization in the 
sense of progressively relaxing the idealizing assumptions. While I believe that it does not ultimately succeed in providing eliminative microfoundations for macroeconomics, there is a case to answer. Before investigating that case, let us consider idealization more generally.

\section{Formal and Substantive Idealization}

\subsection{FORMAL IDEALIZATION}

One account of idealization in science is found, for example, in the work Leszek Nowak (1980). ${ }^{4}$ Let $G(x)$ be a complete theory and $F(x)$ and idealized theory; and let $H_{i}, i=1,2$, $\ldots, n$, denote primary factors and $p_{j}, j=1,2, \ldots, k$, denote secondary factors. Then, then a complete theory is idealized by setting secondary factors to their limits $(0$ or $\infty$, but represented without loss of generality as $p_{j}=0$ ). Thus, the relationship between the idealization and the complete theory is given by,

(4) if $G(x)$ and $p_{1}(x)=0$ and $p_{2}(x)=0$ and $\ldots p_{k-1}(x)=0$ and $p_{k}(x)=0$, then $F(x)=f\left(H_{1}(x), H_{2}(x), \ldots, H_{n}(x)\right)$.

For example, if $G(x)$ is the complete theory of planetary motion governed by Newton's laws, then one of the $p_{j}(x)=0$ might state that the diameters of the planets are zero; while their masses would be among the factors indicated by the $H_{i}(x)$.

The idealized theory can be improved in the sense of being brought closer to a full description of reality by progressive concretization. Each concretizing step amounts to eliminating one of the limit conditions represented in the setting aside of secondary factors $\left(p_{z}(x)=0\right)$ and adding a related primary factor $\left(H_{z}(x)\right)$ to the idealized theory with appropriate changes to the function $(f)$ to yield a less idealized theory $\left(F^{\prime}(x)\right)$ :

\footnotetext{
${ }^{4}$ For a critical discussion of Nowak's account of idealization, see Hoover 1994.
} 
(5) if $G(x)$ and $p_{1}(x)=0$ and $p_{2}(x)=0$ and $\ldots p_{z-1}(x)=0$ and $p_{z}(x) \neq 0$ and $p_{z+1}(x)=0 \ldots$ and $p_{k}(x)=0$, then $F^{\prime}(x)=f^{\prime}\left(H_{1}(x), H_{2}(x), \ldots H_{z}(x) \ldots, H_{n}(x)\right)$.

There are then sequences of theories, each less idealized than the last. Progress through such sequences is a process of successive concretization that terminates in the recovery of the full theory.

If such a formal idealization is to do any work in science, the distinction between primary and secondary factors needs to be fleshed out and some sort of coherence requirement needs to be placed on the idealized theory. Otherwise, the exercise is easily trivialized. Formally, we could simple switch the roles of primary and secondary factors, and could still recover the full theory through successive concretization. By a coherence requirement, I mean that there must be a sense in which the work that can be done by the idealized theory is similar to that done by the complete theory. For example, computations using the idealized theory of planetary motion are able to predict to some desired level of approximation the observed orbital paths even if, because of idealization, they have nothing whatever to say about tides or wobbles of the planetary axes. Without such a requirement, any set of propositions that could be written in the nested structure of (4) would count as an idealization, even if it lacked all explanatory power. There is a sense in which the idealization must, to use Plato's metaphor, take the world apart a the joints. The idealization must get to the essence of the matter. One advantage of the formal analysis is that it suggests that there may be more than one way to idealize, more than one essence of the matter (a point made specifically by Franklin-Hall 2008 and in other contexts by Teller 2001 and Woodward 2003, ch. 5).

Formal accounts of idealization imply that the complete theory $(G(x))$ is known, so that idealization is a matter of the setting side of known secondary factors. Such a 
conception is impractical: frequently, we do not know - except perhaps in a broad brush way - exactly what we are idealizing away. In practice, idealization is less a matter of subtracting away considerations from a complete theory than of building up a simplified model.

The terms "theory" and "model" are fraught (see for example, Hausman's 1992, ch. 5, discussion in relation to economics). Without trying to resolve the issue of how best to use these terms, I have so far adopted what I believe to be the vernacular among economists. "Theories" in this usage are more abstract; "models" are concrete and instantiate general theoretical lessons in particular forms for particular pragmatic purposes. Models are tools for reasoning. Most models provide practical algorithms for deriving concrete conclusions or rules for manipulation and heuristics for drawing analogies between the model and modeled phenomena.

On this view, models are not idealizations, though they may in some sense participate in idealizations. For some purposes an ideal triangle is a polygon with three straight sides setting aside any reference to its particular angles or the lengths of its sides. Such an idealized triangle may figure in geometric proofs. But a model of a triangle (for example, a diagram or a manipulable object) cannot be ideal in the same way. It will be imperfect; its sides for example, not being straight except within some limits of approximation. And it will be particular: it must have definite angles and lengths of sides. Such a model functions as an idealization only under some self-denying ordinances or interpretive protocols that eschew conclusions that depend on the particular, non-ideal features. 


\subsection{SUBSTANTIVE IDEALIZATION}

The relationship between the model triangle and the ideal triangle suggests another form of idealization that we might call substantive idealization. Galilean idealizations are substantive in that they amount to isolating causal mechanisms from disturbing casual influences to exhibit their operation in a pure form (McMullin 1985; Cartwright 1989, ch.

5). Sometimes such isolations are understood theoretically so that they are closely analogous to the formal idealizing steps of Nowak's formulation (4). But sometimes we know only phenomenal, not theoretical, relationships, which are used instrumentally to eliminate causal disturbances. Other times we appeal to general strategies of isolation such as shielding or randomization that we believe will eliminate a range of non-specific disturbances. At all times, we simply hope that our substantive idealizations have not left out any important, but unknown, disturbing factor.

Where formal idealizations are qualitative and abstract, the promise of substantive idealizations is that they might be quantified and engaged with concrete situations (e.g., experiments) or models. Substantive idealization is correlative to approximation. A substantively idealized model is successful if it fits the data or predicts, or meets some other measure of differential empirical success, well enough within some acceptable limits of approximation, provided that its success is traceable to - that is, depends essentially on - the model. The idealization of the distance of fall of a dense sphere according to Newton's laws as distance $=1 / 2 \times g \times t i m e^{2}$ is successful if, up to the limits of approximation we care about, it fits the data as well as a less idealized relationship that, say, took account of air resistance and if the successful fit would not have been 
achieved through an alternative characterization, say, a linear one such as distance $=1 / 2 \times$ $g \times$ time.

The notion of dependency is essentially fuzzy, since there are variations in the relationship that will be indistinguishable within any particular limits of approximation. Yet, such a distinction is needed with respect to substantive idealization for the same reason that the distinction between primary and secondary factors was needed in Nowak's account of formal idealization.

\section{The Idealized Reduction of Macroeconomics to Microeconomics}

Standard graduate textbooks in macroeconomics are not usually methodologically selfconscious. They may nonetheless provide an implicit argument in support of microfoundations. The well known graduate textbook Blanchard and Fischer's Lectures on Macroeconomics (1989, ch. 2) opens with a representative-agent model of economic growth. We have already seen that, without further defense, such a model provides an unattractive account of microfoundations. Yet, in later chapters, Blanchard and Fisher provide alternative models, ostensibly grounded in individual agents. To the extent that such models are successful and do not contradict the conclusions of representative-agent models, they constitute both successful microfoundations and a defense of the representative-agent model. Since these models, do not in fact characterize each and every agent in an economy, they are best understood as employing a strategy of idealization. We now examine the nature of those idealizations, arguing that they are ultimately unsuccessful, so that they do not provide - and a fortiori representative-agent models do not provide - workable microfoundations for macroeconomics. 


\subsection{The Fundamental IDEALIZATION OF ECONOMICS}

Economics is itself founded on an idealization sometimes referred to as "rational economic man." The essence of the idealization is that economic actions are viewed as optimal choices under binding constraints. Karl Popper (1976) generalized the economists idealization under the title "situational logic" or "situational analysis" to be the method of the social sciences: characterize a situation and a goal, and then predict what people will do as the best means of achieving the goal in that situation (Koertge 1979). Popper was fully aware that this was an idealization in the sense that actual agents deviated from the analysis frequently.

Historically, rational economic man was regarded not as a true description, but as an idealization. Mill, Jevons, and Marshall all recognized a hierarchy of human motives or values, of which they saw the economic as being the lowest, but also the broadest and most pervasive. While they did not use the terminology of idealization, they nevertheless saw constrained-optimization as a substantive idealization. It captured a real tendency in human behavior, which dominated but did not completely determine, certain individual and social outcomes. Reasoning based on such a pervasive motive was, therefore, a good enough approximation for many purposes and many circumstances.

\subsection{MiCROECONOMICS IDEALIZATIONS}

The centrality of the constrained-optimization idealization explains the persistent urge to discover the microfoundations of macroeconomics. Blanchard and Fischer (1989, ch. 8) provides a nice exemplar of a microfoundational reduction of macroeconomics. In the 
interest of pedagogical clarity, their account is schematic, omitting many details that may be repaired in obvious ways.

Blanchard and Fischer's reduction also calls on idealizations of a higher order that is, ones that apply within microeconomics qua microeconomics and are not particular to the reduction of macroeconomics to microeconomics. The primary such idealization is the form of competition, which is treated in nearly every microeconomics textbook. Consider the sole producer of a good (a monopolist). The monopolist faces the entire market demand and to maximize profits chooses a price or a quantity to produce (one implies the other as a function of demand) that balances the increase in net revenue per unit as prices rise against the fall in the number of units sold. If we consider two or more producers (duopoly or oligopoly) of the same type of good, we introduce the problem of their interaction - the optimal behavior of each depends on the choices of the others. To reach any definitive conclusion, some assumption about how producers behave in oligopolistic situations is introduced.

The most common assumption derives from Cournot (1838[1929]): each producer takes the other producers' quantity decisions as fixed and unaffected by its own choice; it then chooses the quantity that maximizes profits. An equilibrium occurs when each firms' best response is to maintain its current response and every firm charges the same price. Each firm's optimization problem can be described as a reaction function of their quantities to a common market price.

Cournot's assumption or other alternative should not be regarded as idealizations in Nowak's sense. Rather they are particular, non-ideal features similar to the particular angles that must be incorporated into a manipulable model triangle. Once in place, 
however, they may help sustain idealization. Take the Cournot oligopoly solution as a starting point and let the number of identical producers of identical goods $(n)$ rise without limit $(n \rightarrow \infty)$. Producers are then seen as infinite in number and infinitely small relative to the market. Unlike the monopolist at the $n=1$ extreme, their quantity decisions do not individually affect price, so they simply take prices as given by the market and give their best quantity response. This is clearly a Nowakian idealization in which market power (the ability to affect the demand for one's own product) is idealized away by taking the number or firms to an extreme limit. Market prices themselves "emerge" from the interaction of these highly disaggregated producers' reaction functions, which aggregate to market supply, and the similarly highly disaggregated consumers' reaction functions, which aggregate to market demand.

Monopolistic competition differs from perfect competition in that goods are seen as multidimensional, so that they may have features in common with other goods and yet have other features that make them distinct. Different brands of beer, for instance, are similar and, in that respect, compete with other brands; yet Heineken is unique in its particular formulation, and the Heineken company is the sole purveyor (monopolist) of the brand. Monopolistic competition is the analogue of perfect competition when goods have this multidimensional form: each producer is a monopolist of its own particular good, which nevertheless competes with other related goods. Under perfect competition, any price above the market price would result in no sales; while any price below the market price would capture all market demand. In contrast, under monopolistic competition, consumers may not go for the cheapest good: it may be worth paying more for a Heineken than a Miller Lite - the two brands are imperfect substitutes. Indeed, a 
consumer may diversify consumption according to the interaction of strength of relative preference and price. So, like a monopolist, the producer must set its price to balance the gains of higher prices to unit revenue against the losses of reduced demand. The assumption of price-taking is given up in favor of price-setting, even though the producer remains small relative to the market.

Monopolistic competition can be seen as a less idealized model than perfect competition. If we could give a measure of the differentia among goods, then perfect competition would be the Nowakian limit case in which the differences among goods approached zero.

\subsection{A Reduction of Macroeconomics to Microeconomics}

We now turn to the roles perfect competition and monopolistic competition, among other idealizations, in the reductions of macroeconomics to microeconomics.

Blanchard and Fischer's (1989, ch. 8) model assumes monopolistic competition, but a parallel development could easily be provided for a model using perfect competition.

The first step in their reduction is the idealization that goods are identical in production technology, yet are multidimensional in a way that makes them imperfect substitutes. For example, every type of beer might use the same brewery technology and have the same unit costs of production, even though their recipes differed so that each appealed to some customers more than others. The identicalness of goods on the dimension relevant to production can be seen as a Nowakian idealization, like the 
analogous assumption of identical firms in the microeconomic model of perfect competition.

Many of the key issues of macroeconomics are captured in the next step.

Individual preferences are given by a utility function of the form:

$$
U_{i}=\left(\frac{C_{i}}{g}\right)^{g}\left(\frac{M_{i} / P}{1-g}\right)^{1-g}-\left(\frac{d}{\beta}\right) Y_{i},
$$

where $i=1,2, \ldots, n$ indexes individual consumer/producers; $M_{i}=$ money holdings by the $i^{\text {th }}$ consumer/producer; $Y_{i}=$ output of good $i$ produced by the $i^{\text {th }}$ consumer/producer; $C_{i}=$ "consumption" and is defined by a function that aggregates the consumption of particular goods:

$$
C_{i}=n^{1 /(1-\theta)}\left(\sum_{j=1}^{n} C_{i j}^{(\theta-1) / \theta}\right)^{\theta /(\theta-1)} ;
$$

where $C_{i j}=$ the consumption of good $j$ by agent $i$; and $P$ is the general price level, defined as a weighing of the prices of individual goods $\left(P_{i}\right)$ :

$$
P=\left(\frac{1}{n} \sum_{i=1}^{n} P_{i}^{1-\theta}\right)^{1 /(1-\theta)} .
$$

The functional forms of the model are governed by the parameters $d, g, \beta$, and $\theta$.

The particular functional forms of equations (5) and (6) are familiar to economists: (5) is a Cobb-Douglas utility function with an additional linearly separable term in $Y_{i} ;(6)$ is a constant-elasticity of substitution aggregator function. These forms are chosen not as idealizations of some actual preference function but as tractable forms with well-known mathematical properties, some of which may be adjusted to approximate features of actual preferences. They are then stipulated, non-ideal characteristics 
(particular concretizations) of the model. Other features amount to similar particular concretizations.

- $\quad$ setting the number of producers, goods produced, and consumers to the same number $(n)$;

- putting money holdings in the utility function without any attempt to model the manner in which money facilitates trade (although dividing money by a general price level $(P)$ is meant to capture the characteristic feature of money that its effective (or real) quantity depends on what it will buy;

- treating the costs of production as expressible only as a disutility associated with the level of production of the consumer/producer's single produced good, rather than directly connecting production to labor or other inputs to production.

Each of these assumptions may be regarded as a pedagogical trick, which helps to make the model more tractable, but which in principle could be relaxed or replaced with a more empirically relevant assumptions in straightforward ways. They do not seem to raise special problems for the project of microfoundations.

The model is closed by treating agents as maximizing (5) subject to a budget constraint:

$$
\sum_{j=1}^{n} P_{j} C_{i j}+M_{i}=P_{i} Y_{i}+\bar{M}_{i}=I_{i}
$$

where $\bar{M}_{i}=$ initial endowment of money for the $i^{\text {th }}$ agent. Equation (8) says that income $\left(I_{i}\right)$ consists of the value of what agents sell $\left(P_{i} Y_{i}\right)$ plus the money they start with and that income is in turn divided between money spent on individual goods $\left(P_{j} C_{i j}\right)$ and money saved $\left(M_{i}\right)$. From this optimization problem, Blanchard and Fischer are able to derive 
demands for each good (and for holdings of money) for each consumer and the supply of each good for each individual producer - each as a function of the price of goods relative to the general price level $(P)$.

A systemic solution can be viewed in two ways. First, as a general equilibrium, the model can be solved for a set of prices that makes the supply and demand for each good and for money equal, taking all agents into account. This is a quintessentially microeconomic solution. The actual derivation rests on symmetry. Since every good is produced using the same production technology and each enters into the individual's utility functions with the same weight and all individuals are identical, each should have the same price in equilibrium. Equation (7) then guarantees that the price of each individual good and the general price level are identical, so that all relative prices are unity.

A second way to view the solution calculates various aggregates. Nominal aggregate demand for goods $(Y)$ is by definition the sum over all goods and agents of the value of desired consumption, and is converted to a real value by deflating by the general price level:

$$
Y \equiv \sum_{i=1}^{n} \sum_{j=1}^{n}\left(\frac{P_{j} C_{i j}}{P}\right)=g\left(\frac{I_{j}}{P}\right) .
$$

Making use of the forms of the individual demand functions (not shown), the equality of aggregate demand and output, and the symmetry of prices (implying that relative prices are unity) allows the derivation of aggregate demand functions in which no individual prices appear - for the output of goods:

$$
Y=\left(\frac{g}{1-g}\right)\left(\frac{\bar{M}}{P}\right)
$$


and for money:

$$
M=(1-g)(P Y+\bar{M})
$$

Individual price and output decisions can be derived as part of the solution to the consumers'/producers' optimization problems. In conjunction with the definition of the price level $(P)$, an aggregate supply function relates the price level to the supply of money:

$$
P=\left(\frac{\theta-1}{\theta d}\right)^{1 /(1-\beta)}\left(\frac{g}{(1-g) n}\right) \bar{M}
$$

Together the macroeconomic system (10)-(12) determine the principal aggregates in the economy. The macroeconomic description has supposedly been reduced to the microeconomic in that the macroeconomic system is derived directly from the microeconomic general equilibrium solution to equations (5)-(8). Each of the macroeconomic variables is an aggregation of the microeconomic variables, and the functional forms of the macroeconomic relations are determined by the functional forms and parameters of the microeconomic relationships.

Since idealizing assumptions were involved in the microeconomic model, the reduction is itself idealized. But the model is taken to be a starting point for a model that will concretize a sufficient number of these idealizations until it will serve as a substantive idealization - in this case a model that provides a close enough approximation to the world that it can rationalize actual macroeconomic data.

One example of such improvability, one concretizing step, was the move from the idealization that all the goods are identical, giving a model of perfect competition, to one in which goods are distinct in a manner that supports monopolistic competition. Later in the same lecture, Blanchard and Fischer further concretize the ideal assumption of 
perfectly flexible prices with assumptions about the costs of price setting that result in models in which prices adjust slowly to shocks to the system (e.g., to a change in $\bar{M}$, the money supply).

\subsection{DOES THE IDEALIZATION WORK?}

Blanchard and Fischer's microfoundational reduction involves a number of idealizing steps that are consistent with the goal of achieving substantive idealization. Whether the model is sufficiently concretized on these dimensions is not an a priori conceptual matter, but a matter for empirical investigation and resolution. The reduction nonetheless involves two steps that do raise conceptual difficulties.

The first is reflected in the utility function (equations (5)) that treats the consumption and production decisions as the integrated choice of a single agent. The microreduction views this step as a way of capturing the insight that coordination among agents is essential to macroeconomics. In their formulation, part of the coordination is guaranteed through collapsing the decisions of some firms and consumers (typically different agents in the real economy) into a single optimization problem. While the collapse eliminates any conflict in the choices of particular firm-consumer pairs, the monopolistic competition model at the heart of Blanchard and Fischer's reduction appears to leave room for other conflicting choices by having many such pairs.

Yet there is less here than meets the eye. The model can be viewed as a Nowakian idealization of a Walrasian general-equilibrium model in which producers and consumers are all separate agents. Even at this disaggregated extreme, a genuine coordination problem fails to arise. To see this, consider the perfectly competitive, rather 
than the monopolistically competitive, case. Here we can push the idealization further and collapse the individual agents into a single, representative agent. The coordination issue is then eliminated, since the economy is governed by a single optimization problem. This is clearly unattractive and accounts for our dismissing the representative-agent model in the first case. But is the general-equilibrium extreme any better?

Consider the general-equilibrium analogue to the representative agent's optimization problem. Individual agents, solving individual optimization problems provide part of the coordination. They do not, however, provide all of it. In the idealization, the agents are price-takers, each too small to affect the market on its own. Somehow their choices must be made mutually consistent. The explicit mechanism is that they face a set of common prices, and those prices are adjusted until excess supplies and demands are eliminated. The explicitly modeled agents set quantities in response to market prices, but who sets market prices? And on the basis of what knowledge?

Economic theorists offer two approaches to these questions. First, sometimes they simply abstract away from the process of price setting and focus only on the equilibrium states, asserting that they exist and that comparisons among equilibria are the salient ones, without considering how an equilibrium is established. Equilibrium is deus ex machina. Nonetheless, even the mathematics of discovering equilibria in formal general-equilibrium models points to the character of the god in the machine. Equilibria are proved by establishing a mapping from vectors of prices (one per good) to vectors of prices, in which the mapping increases some prices for which the demand of the corresponding commodities exceeds the available supply at the original vector of prices. If the mapping meets certain regularity conditions, then a fixed-point theorem can be 
invoked to deduce that there exists a price vector that will be mapped into itself and for which all excess demands (and, therefore, supplies) are zero. The market is said to clear.

The mathematics demonstrates that far from economizing on information, something in the economy must process a great deal of information if it is going to be closely analogous to a general-equilibrium model. The second approach to price setting is to give this god a name. On a smaller scale, we are familiar with auctions, in which the processing of price information is handled in exactly the way envisaged in the prices-toprices mapping. Hence, our god is sometimes referred to explicitly as "the auctioneer." Other stories are sometimes told, but they are the functional equivalent of the auctioneer. Here the representative agent is turned into Hobbes's great Leviathan - not the representative agent, but the representative dictator. The representative dictator is not an idealization of the exchange process of macroeconomics, in which the possibility of inconsistent decisions is a live one. Rather - implicitly or explicitly - it is a particular, and particularly unhelpful, concretization, which suggests falsely that the best analogue to a decentralized economy is a command economy along the lines of the Soviet Union or North Korea.

Once again, the case of monopolistic competition, as in Blanchard and Fischer's model, may seem different, since price-setting is decentralized, prices being a choice variable for the $n$ consumer-producers. Unfortunately, our monotheistic coordinating god or dictator has simply assumed a polytheistic form. The equilibrium value of the aggregate price level in equation (12) is derived from its definition (equation (7)) and the optimal price for each consumer-producer: 


$$
\frac{P_{i}}{P}=\left(\left[\frac{d \theta}{\theta-1}\right]\left[\left(\frac{g}{(1-g) n}\right) \frac{\bar{M}}{P}\right]^{\beta-1}\right)^{\frac{1}{1+\theta(\beta-1)}} .
$$

Two things should be noted. First, the functional form of this individual optimization problem depends on the parameters of the utility function (5), and may thus seem to refer only to the individual and to represent a small volume of information: $\theta, d$, $g$, and $\beta$ do not seem like much to know, especially since they correspond to data available to actual people through introspection. The simplicity is deceptive, since it results from the assumption that all agents are identical. If that assumption were relaxed, then the parameters of every agent would show up in the analogue to (13). This is obvious, since the monopolistic competitor sets prices on the basis of a demand curve for its product that depends on the demands of every consumer and the supply responses of all of its competitors.

Second, application of equation (13) requires knowledge of the general price level $P$, and as (7) shows $P$ is constructed through a complex weighting of the individual prices $\left(P_{j}\right)$. In fact, equation (7) is a rather odd aggregating function that bears no obvious relationship to any of the standard formulae for calculating price indices used, for example, by national statistical bureaux. The form of (7) is, in fact, dictated by a macroeconomic consideration: $P$ is defined in just such as way as to make aggregate monetary expenditures on goods equals aggregate monetary incomes $\left(\sum_{i} P C_{i}=\sum_{i} \sum_{j} P_{j} C_{j i}\right)$, a condition required by national-income-accounting conventions. ${ }^{5}$ The general price level is, thus, an irreducible macroeconomic quantity, which cannot be

\footnotetext{
${ }^{5}$ See Nelson (1984) for a discussion of microreductions that are constrained by macroeconomic relationships.
} 
eliminated from the reduction in the sense that individual agents must refer to an aggregate - to the whole - in order to make their individual choices. In fact, its units are not analogous to the units of any individual price. I have previously argued that the general price level is an emergent property of macroeconomic systems and ontologically distinct from, while nonetheless supervenient on, the prices of individual goods (Hoover (1995; 2001b, ch. 5).

The implicit assumption, then, is that far from succeeding in decentralizing the processing of knowledge and price setting, the microfoundational reduction based on monopolistic competition has put each consumer-firm in a position analogous to the auctioneer, who must know everyone's business. Any objection to the auctioneer in the setting of perfect competition must be multiplied by $n$ in the setting of monopolistic competition. Rather than isolating the essence of the coordination problem, the microreduction dissolves it with a particular assumption that amounts to assuming it away. The situation is much the same as if we offered a figure as an idealized triangle, but neglected to give it three sides.

The second conceptual difficulty of the microreduction concerns aggregation. Again, it helps to start with perfect competition. The assumption that agents are price takers and small relative to the market is a properly formulated Nowakian formal idealization and may, in practice, prove to be a useful substantive idealization. In contrast, the argument that justifies the representative-agent assumption through an idealization in which general equilibrium stands at one limit and the representative-agent at the other introduces an improper idealization. The representative agent is held to follow the rule of perfect competition, price-taking, which is justified on the idealizing 
assumptions that $n \rightarrow \infty$; yet the representative agent is itself an idealization in which $n \rightarrow 1$. The representative agent is - inconsistently - simultaneously the whole market and small relative to market. The problem can be summed up by the question: with whom does the representative agent trade?

Another aspect of the problem can be seen by noting that the acceptable idealization of perfect competition in microeconomics applies to markets for particular goods, while macroeconomics must somehow capture the economy as a whole. This, as we have seen before, suggests that the idealization should start with a general equilibrium system in which there are many different goods. The model would then involve two idealizations. The first lets the number of distinct goods approach a limit at one. The second lets the diversity of types of agents approach a single type, while letting there still be $n$ agents. Aggregation might then appear simple. Aggregate demand would equal $n \times$ individual demand, and aggregate supply would equal $n \times$ individual supply. The aggregation would be justified if it yielded a good enough approximation for the purposes at hand. Economics textbooks not infrequently speak of such modeling assumptions often referring to the single good as some ubiquitous commodity - e.g., "corn" or "steel."

As we have already noted in Section II, aggregation theory tell us that adding up of individual demands or supplies to a well behaved aggregate demand or supply requires the strong assumption of homotheticity as well as identical goods and agents. Otherwise, as prices, and consequently incomes, change, the aggregates themselves would change and the representative agent's optimization problem and resulting demand and supply functions would no longer take the same form (just scaled up) as a particular agent's optimization problem and resulting functions. The requirement of homotheticity is not a 
Nowakian idealization. It does not eliminate a substantive factor as inessential by setting it to a limit. Instead, it is a particular concrete assumption upon which the result critically depends. And it is not robust or an attractive prospect for a useful approximation.

Once again, the move toward monopolistic competition does not resolve the problem. Blanchard and Fischer assume identical agents and posit homothetic utility functions. Although they do not assume that goods are identical, the goods are identical in the only ways that matter for aggregation. So, like our previous example of different types of beer, their goods are identical in production requirements, and they enter perfectly symmetrically into utility functions. These strong assumptions trivialize the variety of goods in the real-world, but create the precise conditions needed for aggregation. With perfect competition, we derived the representative agent through an improper idealization. We could rationalize the representative agent through a microreduction that made stronger, particular and nonidealizing assumptions. And even though, Blanchard and Fischer, in this particular model, do not posit a representative agent, we find that they make essentially the same strong, particular, and nonidealizing assumptions in order to provide a microfoundation for the relations of macroeconomic variables. The idealization strategy collapses into the representative-agent strategy.

\section{Microfoundations - A Less Than Ideal Reduction}

The idea that macroeconomics not only needs microfoundations, but that microeconomics can replace macroeconomics completely is the dominant position in modern economics. No one, however, knows how to derive empirically relevant explanations of observable aggregate relations from the precise individual behaviors that 
generate them. Instead, the claims to have produced microfoundations are typically fleshed out with representative-agent models in which a single agent treats the aggregates as objects of direct choice, playing by rules that appear to follow the logic and mathematics of microeconomics. It is easy to mock the representative agent. But the defense that is sometimes offered is to provide models that employ a number of idealizing assumptions and appear to either deliver a representative-agent model or an account of unproblematic aggregation.

I accept idealization as a strategy of model building. But legitimate idealization requires that the idealized model capture the essence of the causal structure or underlying mechanisms at work. It is only on that basis that we can trust the model to analyze situations other than the data to hand. And that rationale is precisely what is behind the call for microfoundations in the first place. Models are not, of their nature, cleanly idealized; they must involve particular properties, whose only function is to make them operable or realizable in a manipulable form. Arbitrary concretizations are unavoidable. A model with utility maximizing agents, must give the utility functions a form. Yet, the trick of using models appropriately is that we should either be able to set aside these particularities in reasoning or show that the results of interest are robust to the range of particular forms that we might reasonably assume. To return to a previous example: a model of a triangle includes particular angles; yet any conclusions that we derive from our model about triangles in general or about some particular triangles in the world which we have no reason to believe are congruent to our model cannot depend critically on those particular angles. 
The essence of the criticism of the common strategies of reducing microeconomics to macroeconomics is that it is based in model building that mixes legitimate idealizations with non-ideal, particular modeling assumptions and then relies on those assumptions at critical junctures in providing the derivation of the macroeconomic relationships from microeconomic behaviors.

\section{References}

Arrow, Kenneth. (1951) Social Choice and Individual Values. New York: Wiley.

Blanchard, Olivier and Stanley Fischer. (1989) Lectures on Macroeconomics. Cambridge, MA: MIT Press.

Cartwright, Nancy. (1989) Nature's Capacities and Their Measurement. Oxford: Clarendon Press.

Cournot, Antoine Augustin. (1838[1929]). Researches into the Mathematical Principles of the Theory of Wealth. N.T. Bacon, translator. New York: Macmillan.

Duarte, Pedro Garcia. (2007) "Visiting Frank P. Ramsey: The Public Finance Concept of Optimal Monetary Policy,", working paper downloadable from the Social Sciences Research Network: http://ssrn.com/abstract=985331

Franklin-Hall, Laura. (2008) "Plato’s Joints," unpublished manuscript, http://www.columbia.edu/ /rf2001/PlatosJoints.pdf.

Gorman, William. M. (1953) “Community Preference Fields,” Econometrica, 21(1), 6380.

Hartley, James E. (1997) The Representative Agent in Macroeconomics. London: Routledge.

Hausman, D.M. (1992). The Inexact and Separate Science of Economics. Cambridge: Cambridge University Press.

Hoover, Kevin D. (1988) The New Classical Macroeconomics: A Sceptical Inquiry. Oxford: Blackwell.

Hoover, Kevin D. (1994) "Six Queries About Idealization in an Empirical Context," Poznan Studies in the Philosophy of Science and the Humanities, vol. 38, pp. 43-53.

Hoover, Kevin D. (1995) “Is Macroeconomics for Real?” The Monist 78(3), 235-257.

Hoover, Kevin D. (2001a) The Methodology of Empirical Macroeconomics. Cambridge: Cambridge University Press. 
Hoover, Kevin D. (2001b) Causality in Macroeconomics. Cambridge: Cambridge University Press.

Hoover, Kevin D. (forthcoming), "Microfoundations and the Ontology of Macroeconomics," in Harold Kincaid and Donald Ross, editors, Oxford Handbook of the Philosophy of Economic Science. Oxford: Oxford University Press.

Microfoundations: A Critical Inquiry. By Maarten C. W. Janssen. London and New York: Routledge, 1993.

Keynes, John Maynard. (1936) The General Theory of Employment Interest and Money. London: Macmillan.

Kirman, Alan P. (1992) "Whom or What Does the Representative Individual Represent?," Journal of Economic Perspectives, 6(2), 117-36.

Klein, Lawrence R. (1947) The Keynesian Revolution. New York: Macmillan

Koertge, Noretta. (1979) “The Methodological Status of Popper's Rationality Principle," Theory and Decision 10(1), 83-95.

Leontief, Wassily. (1936) “The Fundamental Assumption of Mr. Keynes's Monetary Theory of Unemployment," Quarterly Journal of Economics, 51(1), 192-197.

Lucas, Robert E., Jr. (1976) "Econometric Policy Evaluation: A Critique," reprinted in Lucas, Studies in Business Cycle Theory. Oxford: Blackwell, pp. 104-130.

Lucas, Robert E., Jr. (2004) "My Keynesian Education," Michel De Vroey and Kevin D. Hoover, editors. The IS-LM Model: Its Rise, Fall, and Strange Persistence. Durham, NC: Duke University Press.

McMullin, Ernan. (1985) “Galilean Idealization," Studies in the History and Philosophy of Science 16, 247-273.

Alan Nelson. (1984) "Some Issues Surrounding the Reduction of Macroeconomics to Microeconomics,” Philosophy of Science, 51(4), December, 573-594.

Nowak, Leszek. (1980). The Structure of Idealization: Towards a Systematic Interpretation of the Marxian Idea of Science. Dordrecht: Reidel.

Popper, Karl. (1976) "The Logic of the Social Sciences," in T.W. Adorno, editor. The Positivist Dispute in German Sociology. London: Heinemann, pp. 87-104.

Ramsey F.P. (1928), "A Mathematical Theory of Saving," Economic Journal, 38(152), 543-559

Robbins, Lionel. (1935). An Essay on the Nature and Significance of Economic Science. London: Macmillan.

Teller, Paul. (2001) “Twilight of the Perfect Model Model,” Erkenntnis 55(3), pp. 393415.

Waters, C. Kenneth. (2000) "Molecules Made Biological," Revue Internationale de Philosophie 4(214), 539-564.

Woodward, James B. (2003) Making Things Happen: A Theory of Causal Explanation. Oxford: Oxford University Press. 